\title{
DEXMEDETOMIDINE AS AN ADJUVANT TO EPIDURAL ROPIVACAINE IN LOWER LIMB SURGERIES- A RANDOMISED CONTROL TRIAL
}

\author{
Susanta Sarkar1, Subhrajyoti Chattopadhyay², Saptarshi Bhattacharya ${ }^{3}$, Mohanchandra Mandal', Piyali Chakrabarti 5 , Suchitra Pal ${ }^{6}$ \\ ${ }^{1}$ Associate Professor, Department of Anaesthesiology, North Bengal Medical College, Sushrutanagar, Darjeeling, West Bengal, India. \\ ${ }^{2}$ Associate Professor, Department of Anaesthesiology, North Bengal Medical College, Sushrutanagar, Darjeeling, West Bengal, India. \\ 3 Junior Consultant, Department of Anaesthesiology and Critical Care, Medica Superspecialty Hospital, Kolkata, West Bengal, India. \\ ${ }_{4}^{4}$ Associate Professor, Department of Anaesthesiology, North Bengal Medical College, Sushrutanagar, Darjeeling, West Bengal, India. \\ 5 Postgraduate Trainee, Department of Physiology, North Bengal Medical College, Sushrutanagar, Darjeeling, West Bengal, India. \\ ${ }^{6}$ Nursing Sister, Department of Psychiatry, Central Hospital, SE Railway, Garden Reach, Kolkata, West Bengal, India.
}

\section{ABSTRACT}

\section{BACKGROUND}

Epidural anaesthesia is now increasingly being used for lower limb surgeries for its certain advantages. Different adjuvants have been used with epidural ropivacaine to prolong the intraoperative and postoperative analgesia. Evidence is growing in favour of dexmedetomidine as an epidural adjuvant. Different doses of dexmedetomidine have been used with epidural ropivacaine with variable success in modifying the block characteristics and adverse event profile.

The aim of the present study was to compare the block characteristics between epidural ropivacaine with dexmedetomidine $(2 \mu \mathrm{g} / \mathrm{kg})$ as adjuvant and epidural ropivacaine alone in patients undergoing lower limb surgeries.

\section{MATERIALS AND METHODS}

In this randomised, double-blinded study, 88 adult patients of either sex, aged between 40-65 years, scheduled for elective lower limb surgery under epidural anaesthesia, were randomly allocated into two groups to receive either $0.75 \%$ ropivacaine alone (Group A) or dexmedetomidine ( $2 \mu \mathrm{g} / \mathrm{kg}$ ) as an adjuvant to ropivacaine $0.75 \%$ (Group B) in epidural space. Data from 40 patients of each group were finally analysed. The time to achieve $\mathrm{T}_{6}$ sensory block (Primary outcome), time to reach maximum sensory block, time to achieve complete motor block, time to two-segment regression of sensory block and duration of analgesia were noted in all cases. The incidences of adverse events such as nausea, vomiting, hypotension, dry mouth, bradycardia, desaturation, respiratory depression, etc. were also noted. Statistical analysis was performed using independent sample Student's ' $t$ ' test for normally distributed variables and Pearson Chi-square test for categorical data. The level of significance was set as $\mathrm{P}<0.05$.

\section{RESULTS}

The time to achieve sensory block at $\mathrm{T}_{6}$ level in group B $(9.45 \pm 1.04$ minutes) was significantly shorter than group A (13.65 \pm 1.12 minutes), $\mathrm{P}<0.05$. The time to achieve maximal sensory block and time to achieve complete motor block were also found shorter in dexmedetomidine group. Sensory block regressed later in dexmedetomidine group compared to control (157.03 \pm 7.87 versus $118.47 \pm 7.32$ minutes, respectively, $\mathrm{P}<0.05)$. The time to first rescue epidural top-up was prolonged in dexmedetomidine group compared with ropivacaine alone group $(346.12 \pm 17.29$ versus $327.98 \pm 17.60$ minutes, respectively). Incidences of adverse events were comparable.

\section{CONCLUSION}

Epidural dexmedetomidine is a reliable adjuvant with ropivacaine $(0.75 \%)$ to provide early onset of sensory block and longer duration of analgesia in lower limb surgeries.

\section{KEYWORDS}

Dexmedetomidine, Epidural Anaesthesia, Lower Limb Surgeries, Ropivacaine.

HOW TO CITE THIS ARTICLE: Sarkar S, Chattopadhyay S, Bhattacharya S, et al. Dexmedetomidine as an adjuvant to epidural ropivacaine in lower limb surgeries- A randomised control trial. J. Evolution Med. Dent. Sci. 2017;6(19):1473-1478, DOI: 10.14260/Jemds/2017/323

\section{BACKGROUND}

Nowadays, regional anaesthesia has become more popular than general anaesthesia for lower limb surgeries as it has

Financial or Other, Competing Interest: None.

Submission 25-01-2017, Peer Review 18-02-2017,

Acceptance 24-02-2017, Published 06-03-2017.

Corresponding Author:

Susanta Sarkar

Flat No. $-B / 2 / 2$,

Himalaya Residency,

Babupara, Siliguri,

West Bengal, India.

E-mail: susantaanesth@yahoo.in

DOI: $10.14260 /$ jemds $/ 2017 / 323$ several advantages such as attenuation of pressor response of airway manipulation, better intra- and post-operative pain management and greater patient satisfaction. ${ }^{1}$ Epidural anaesthesia for lower limb surgery is a well-accepted technique for its certain advantages over spinal anaesthesia, such as better suppression of surgical stress, capability of prolonging intraoperative anaesthesia and postoperative analgesia. 2,3

Bupivacaine is used in epidural route since years long. The new amide local anaesthetic, ropivacaine has minimal cardiovascular and central nervous system toxicity as well as a lesser propensity of motor block during postoperative epidural analgesia compared to bupivacaine. ${ }^{4}$ The addition of opioid in epidural anaesthesia as an adjunct, provides a dose sparing effect of local anaesthetic and superior analgesia but 
there is always a possibility of an increased incidence of nausea, vomiting, pruritus, urinary retention and respiratory depression. ${ }^{5}$ Moreover, the incidence of motor block after epidural analgesia with amide local anaesthetic and opioid is approximately $4-12 \%$, that itself defeats the noble purpose of early rehabilitation. 6

Dexmedetomidine, a new alpha2 agonist, has some beneficial effects when used through epidural route. ${ }^{7}$ It acts on both pre- and post-synaptic sympathetic nerve terminal thereby decreasing sympathetic outflow and norepinephrine release. This action is responsible for sedative, anxiolytic, analgesic, sympatholytic and haemodynamic effects. ${ }^{8}$ Dexmedetomidine does cause a manageable hypotension and bradycardia but the striking feature of this drug is the lack of opioid-related side effects like respiratory depression, pruritus, nausea and vomiting. Dexmedetomidine have been evaluated epidurally without any report of neurological deficit in human being.9,10 The present study was aimed to evaluate the effect of dexmedetomidine as an adjuvant to epidural ropivacaine compared with epidural ropivacaine alone in respect to the onset of sensory block and duration of analgesia in lower limb surgeries. Additionally, the time to reach maximal sensory block, time to complete motor block and time to two-segment regression of sensory block were noted.

\section{MATERIALS AND METHODS}

The present randomised double-blinded study was conducted in a tertiary care centre (Government Medical College \& Hospital) after getting approval from the Institute's Ethical Committee. Written informed consent was obtained from all patients. A total 88 adult patients of American Society of Anesthesiologists physical status I and II, aged between 40-65 years, BMI between 18.5 to $29.9 \mathrm{~kg} / \mathrm{m}^{2}$, scheduled for elective lower limb surgery under epidural anaesthesia, were enrolled for the study. Exclusion criteria were patient's refusal, known coagulopathy, renal or hepatic dysfunction, hypersensitivity to any of the study drugs, known heart disease, diabetes mellitus, pregnancy, seizure disorder and presence of psychiatric illness.

It was assumed that a difference of at least 4 minutes in reduction of onset of sensory block could be clinically relevant. Considering $\alpha$ value 0.05 and setting the power of the study at $80 \%$, we got sample size of 40 for each group. Considering a possibility of a dropout of $10 \%$, total eighty eight (88) patients were enrolled in the study.

During preoperative visit, patient's age, BMI and baseline vitals parameters were recorded. Detailed history was taken; general physical and systemic examinations were done. According to history and clinical examinations, relevant laboratory investigations were carried out for all patients. Then the patients were recruited as per inclusion and exclusion criteria.

The patients were randomly allocated in to two equal groups utilising computer-generated random numbers. Allocation concealment was achieved by placing the random numbers within sequentially numbered, sealed opaque envelopes. The patients were evenly assigned into two groups of equal numbers to receive either preservative free $0.75 \%$ ropivacaine $+0.9 \%$ normal saline (Group $A, n=44$ ) or $0.75 \%$ ropivacaine + dexmedetomidine $2 \mathrm{mcg} / \mathrm{kg}$ (Group B, $\mathrm{n}=44$ ). A person not participating in the study kept the table of random numbers.
The patients were instructed not to consume solid food after midnight on the day before surgery but clear liquids were permitted till two hours prior to scheduled time of operation. Each patient was advised to take Tab. Ranitidine (150 $\mathrm{mg}$ ) in the night before surgery and on the morning of surgery. On arrival of the patient to the operating room, all standard monitors were attached and baseline heart rate (HR), mean arterial pressure (MAP) and oxygen saturation $\left(\mathrm{SpO}_{2}\right)$ were recorded by an investigator who was unaware of the group allocation. After securing intravenous line with 18 G IV cannula, pre-loading was done with $15 \mathrm{~mL} / \mathrm{kg}$ of warm lactated Ringer's solution over 15 minutes before administering epidural block and then $5 \mathrm{~mL} / \mathrm{min}$. to keep intravenous line patent. Anaesthetic machine, breathing circuits were properly checked beforehand. All the resuscitative drugs and equipment including epidural tray containing epidural kit were checked.

The patients were placed in lateral decubitus position. After aseptic dressing and draping, $2 \mathrm{~mL} \mathrm{1 \%} \mathrm{lignocaine} \mathrm{was}$ infiltrated into the skin and subcutaneous tissues at $\mathrm{L}_{3}-\mathrm{L}_{4}$ and $\mathrm{L}_{4}-\mathrm{L}_{5}$ interspaces. Epidural anaesthesia was administered by 18 G Tuohy needle at $\mathrm{L}_{3}-\mathrm{L}_{4}$ or $\mathrm{L}_{4}-\mathrm{L}_{5}$ intervertebral space. After placement of epidural catheter, a test dose of $3 \mathrm{~mL} 2 \%$ lignocaine hydrochloride with adrenaline (1:200000) was injected and vital parameters (HR, NIBP, ECG, $\mathrm{SpO}_{2}$ ) were monitored. After 4-5 minutes after test dose, study drugs were injected through epidural catheter according to the group allocation. Patients in group A received $16 \mathrm{~mL}$ of $0.75 \%$ ropivacaine and $0.9 \%$ sodium chloride to make the total volume of $18 \mathrm{~mL}$. On the other hand, patients in group B received $16 \mathrm{~mL}$ of $0.75 \%$ ropivacaine and $2 \mathrm{mcg} / \mathrm{kg}$ dexmedetomidine and $0.9 \%$ sodium chloride to make the total volume of $18 \mathrm{~mL}$. All the drugs used in the epidural route were preservative free.

All the blocks were performed by the same anaesthesiologist throughout the study and remained unaware of the patient's group assignment. The drugs were prepared in the unlabelled syringes as colourless solutions by a resident who was aware of the group allocation and did not take part in the study. The unlabelled syringes were handed over to the anaesthesiologist (Performing the block) who was kept unaware about the identity of the drug. The patient who was receiving the drug was also not aware of the particular nature of the drug. Thus, the study has been made double blinded.

After the block, patient was made supine and the haemodynamic and respiratory parameters (MAP, heart rate, $\mathrm{SpO}_{2}$ ) were observed and the values were recorded at 5minute interval for first 30 minutes, then at 15-minute intervals for next one and half hours and thereafter every 30 minutes till the end of surgery. The surgery was allowed to start 20 minutes after epidural injection. No sedatives and analgesics were given intravenously.

The primary outcome of this study i.e., onset of sensory block was assessed by bilateral pinprick discrimination with $24 \mathrm{G}$ needle to evaluate the sensory block level at 2-minute interval after the epidural drug administration till to reach $\mathrm{T}_{6}$ level. Secondary outcomes such as time to reach maximum sensory block, time to achieve complete motor block, duration of sensory block (Time to two segment regression of sensory level), and time to complete recovery from motor block, were also noted in all cases.

The incidences of adverse events such as nausea, vomiting, hypotension, dry mouth, bradycardia, desaturation, 
respiratory depression, etc. were noted. Episodes of intraoperative hypotension (Mean arterial pressure decreased more than $20 \%$ of preoperative baseline value), was treated with Inj. Phenylephrine 25-50 mcg IV bolus. Patients with heart rate less than 50 beats/minute with symptoms were treated with Inj. Atropine $0.6 \mathrm{mg}$ intravenously. Nausea (Persisting $>5$ minutes) and vomiting was treated with $6 \mathrm{mg}$ IV ondansetron.

At the end of surgery, patients were shifted to the recovery room where all the necessary parameters were recorded. The first complaint of pain was managed with rescue epidural top-up doses of $8 \mathrm{~mL} 0.2 \%$ ropivacaine; and it was considered as duration of analgesia.

The results of the present study were decoded and tabulated in Microsoft excel work sheet. They were subjected to statistical analysis using SPSS version 12.0 (Chicago, IL, Inc) for windows. All continuous data were presented in the as absolute values or relative number of patients, as appropriate. Comparisons for each demographic and clinical variable between the two groups (Numerical data) were normally distributed variables and Pearson Chi-square test for categorical variables. The level of significance was set as $P$ $<0.05$.

\section{RESULTS}

The present study spanned over approximately one year (From May 2012 to April 2013). Initially it was started with 88 patients, who were randomised into two equal groups, 44 in each group. But four patients from each group received general anaesthesia owing to failed epidural and partial block, resulting in exclusion from the study. Therefore, data from 80 patients were available for final analysis (Group $A=40$, Group $B=40$ ). Both the groups of patients undergoing lower limb surgery were comparable regarding demographic profile (Table 1).

The time to achieve sensory block at $\mathrm{T}_{6}$ level in group $\mathrm{B}$ (9.45 \pm 1.04 minutes) was significantly shorter than group A (13.65 \pm 1.12 minutes) $\mathrm{P}<0.05$. Maximum sensory block reached earlier in dexmedetomidine group compared with ropivacaine-alone group $(12.61 \pm 1.45$ minutes versus $15.55 \pm 1.80$ minutes, respectively; $\mathrm{P}<0.05$ ). The time to achieve complete motor block was also found shorter in patients receiving dexmedetomidine as epidural adjuvant (Group B). Sensory block regressed later in group B compared to group A $(157.03 \pm 7.87$ minutes versus $118.47 \pm 7.32$ minutes, respectively, $\mathrm{P}<0.05)$. Mean time to complete recovery from motor block was found longer in patients receiving dexmedetomidine as epidural adjuvant. The duration of analgesia (Time to first rescue epidural top up) was found to be prolonged in patients receiving dexmedetomidine as adjuvant to epidural ropivacaine (346.12 \pm 17.29 minutes) compared to those receiving ropivacaine alone ( $327.98 \pm 17.60$ minutes). This difference was found to be significant $(\mathrm{P}<0.05)$ (Table 2 and Figure $1 \&$ 2).

Reduction of systolic blood pressure from the baseline values were noted following epidural anaesthesia in both the groups, but it was not statistically significant; $\mathrm{P}>0.05$ (Table 3 ). Heart rate changes were comparable in most of the time points except at baseline, at 15 minutes, at 105 minutes and at 120 minutes. The baseline higher HR in dexmedetomidine group is probably better controlled, thereby the difference tables as mean \pm SD. Discrete categorical data were presented performed by Independent sample Student's ' $\mathrm{t}$ ' test for

became significant at 15 minutes. The significant fall in heart rate at 105 and 120 minutes may be attributed to the effect of dexmedetomidine after absorption from epidural space. However, no concrete inference can be drawn as plasma concentration was not measured (Table 4). Incidence of adverse events was comparable in between two groups (Table 5).

\begin{tabular}{|c|c|c|c|}
\hline $\begin{array}{c}\text { Demographic } \\
\text { Data }\end{array}$ & $\begin{array}{c}\text { Group } \\
\mathbf{A}(\mathbf{n}=\mathbf{4 0})\end{array}$ & $\begin{array}{c}\text { Group } \\
\mathbf{B}(\mathbf{n = 4 0})\end{array}$ & $\begin{array}{c}\mathbf{P} \\
\text { value }\end{array}$ \\
\hline Age (years) & $43.36 \pm 13.27$ & $43.27 \pm 13.92$ & 0.98 \\
\hline Height (cm) & $160.98 \pm 5.78$ & $160.68 \pm 5.48$ & 0.81 \\
\hline Weight $(\mathrm{kg})$ & $63.20 \pm 8.41$ & $63.25 \pm 7.81$ & 0.98 \\
\hline BMI $\left(\mathrm{kg} / \mathrm{m}^{2}\right.$ ) & $24.47 \pm 3.22$ & $24.51 \pm 2.82$ & 0.88 \\
\hline Sex (M/F)* & $23 / 17$ & $25 / 15$ & 0.75 \\
\hline ASA (I/II)* & $24 / 16$ & $22 / 18$ & 0.57 \\
\hline
\end{tabular}

Data expressed as mean \pm SD. Tests done: Independent samples t test. * Data expressed in numbers. Pearson Chisquare test. $(\mathrm{P}<0.05$ considered significant).

Table 1. Demographic Parameters

\begin{tabular}{|c|c|c|c|}
\hline $\begin{array}{c}\text { Block } \\
\text { Characteristics }\end{array}$ & $\begin{array}{c}\text { Group A } \\
\text { (n=40) }\end{array}$ & $\begin{array}{c}\text { Group B } \\
\text { (n=40) }\end{array}$ & P value \\
\hline $\begin{array}{c}\text { Time to achieve } \\
\text { T6 sensory block }\end{array}$ & $13.65 \pm 1.12$ & $9.45 \pm 1.04$ & 0.0002 \\
\hline $\begin{array}{c}\text { Time to reach } \\
\text { maximum sensory } \\
\text { block }\end{array}$ & $15.55 \pm 1.80$ & $12.61 \pm 1.45$ & 0.04 \\
\hline $\begin{array}{c}\text { Time to achieve } \\
\text { complete motor } \\
\text { block }\end{array}$ & $19.33 \pm 1.70$ & $16.85 \pm 2.03$ & 0.005 \\
\hline $\begin{array}{c}\text { Time to two } \\
\text { segment sensory } \\
\text { regression }\end{array}$ & $118.47 \pm 7.32$ & $157.03 \pm 7.87$ & 0.001 \\
\hline $\begin{array}{c}\text { Time to complete } \\
\text { recovery from } \\
\text { motor block }\end{array}$ & $146.11 \pm 15.15$ & $233.99 \pm 19.72$ & 0.002 \\
\hline $\begin{array}{c}\text { Time to first rescue } \\
\text { epidural top up }\end{array}$ & $327.98 \pm 17.60$ & $346.12 \pm 17.29$ & 0.007 \\
\hline $\begin{array}{c}\text { Data expressed as mean } \pm \text { SD. Times are noted in minutes. } \\
\text { Test done: Independent samples t test. } \\
\text { (P < 0.05 considered significant). Group A, patients receiving } \\
\text { epidural ropivacaine alone; Group B, patients receiving } \\
\text { ropivacaine with dexmedetomidine as adjuvant. }\end{array}$ \\
\hline \multicolumn{4}{|c|}{ Table 2. Block Characteristics } \\
\hline
\end{tabular}

\begin{tabular}{|c|c|c|c|}
\hline Parameters & Group A & Group B & P-value \\
\hline MAP_base & $97.15 \pm 5.419$ & $96.88 \pm 3.291$ & 0.785 \\
\hline MAP_5 min. & $92.80 \pm 5.553$ & $91.23 \pm 4.616$ & 0.172 \\
\hline MAP_10 min. & $87.65 \pm 7.23$ & $85.98 \pm 8.969$ & 0.360 \\
\hline MAP_15 min. & $81.80 \pm 11.552$ & $87.68 \pm 9.983$ & 0.199 \\
\hline MAP_20 min. & $75.58 \pm 9.044$ & $75.30 \pm 8.386$ & 0.888 \\
\hline MAP_25 min. & $73.90 \pm 7.376$ & $73.38 \pm 7.618$ & 0.755 \\
\hline MAP_30 min. & $71.00 \pm 6.118$ & $70.97 \pm 6.425$ & 0.972 \\
\hline MAP_45 min. & $75.25 \pm 7.735$ & $84.60 \pm 7.655$ & 0.248 \\
\hline MAP_60 min. & $77.70 \pm 9,087$ & $76.73 \pm 7.369$ & 0.600 \\
\hline MAP_75 min. & $76.35 \pm 7.066$ & $75.78 \pm 7.029$ & 0.716 \\
\hline MAP_90 min. & $79.93 \pm 7.992$ & $81.98 \pm 9.561$ & 0.301 \\
\hline MAP_105 min. & $85.05 \pm 9.061$ & $87.65 \pm 7.213$ & 0.160 \\
\hline MAP_120 min. & $88.65 \pm 6.967$ & $89.60 \pm 8.866$ & 0.596 \\
\hline \multicolumn{4}{|c|}{ Data presented as mean \pm SD, Mean arterial pressure } \\
measured in mmHg. P<0.05 is considered as significant. Test \\
applied- Independent Sample Student's t-test. \\
\hline Table 3. Mean Arterial Pressure over different Time Points \\
\hline
\end{tabular}




\begin{tabular}{|c|c|c|c|}
\hline Parameters & Group A & Group B & P-value \\
\hline HR_base & $78.60 \pm 7.459$ & $83.25 \pm 7.217$ & $0.006^{*}$ \\
\hline HR_5 min. & $82.58 \pm 9.481$ & $80.28 \pm 4.019$ & 0.178 \\
\hline HR_10 min. & $78.70 \pm 9.985$ & $78.38 \pm 3.821$ & 0.848 \\
\hline HR_15 min. & $82.62 \pm 9.737$ & $77.78 \pm 5.650$ & $0.009 *$ \\
\hline HR_20 min. & $78.50 \pm 7.990$ & $81.60 \pm 6.527$ & 0.061 \\
\hline HR_25 min. & $78.20 \pm 9.573$ & $77.33 \pm 8.965$ & 0.674 \\
\hline HR_30 min. & $76.10 \pm 7.993$ & $78.35 \pm 8.702$ & 0.232 \\
\hline HR_45 min. & $76.10 \pm 7.692$ & $79.08 \pm 8.940$ & 0.115 \\
\hline HR_60 min. & $78.30 \pm 7.819$ & $76.28 \pm 8.987$ & 0.286 \\
\hline HR_75 min. & $75.40 \pm 7.306$ & $76.83 \pm 7.805$ & 0.402 \\
\hline HR_90 min. & $76.90 \pm 8.095$ & $75.43 \pm 7.246$ & 0.393 \\
\hline HR_105 min. & $77.10 \pm 7.295$ & $73.55 \pm 6.865$ & $0.028^{*}$ \\
\hline HR_120 min. & $75.50 \pm 6.489$ & $72.40 \pm 7.355$ & $0.049^{*}$ \\
\hline \multicolumn{4}{|c|}{$\begin{array}{l}\text { Data presented as mean } \pm \mathrm{SD} \text {, Heart rate measured in beats } \\
\text { per minute. }{ }^{*} \mathrm{P}<0.05 \text { is considered as significant. } \\
\text { Test applied- Independent sample Student's t-test. }\end{array}$} \\
\hline
\end{tabular}

\begin{tabular}{|c|c|c|c|}
\hline & $\begin{array}{c}\text { Group A } \\
(n=40)\end{array}$ & $\begin{array}{c}\text { Group B } \\
(n=40)\end{array}$ & P value \\
\hline Nausea & 4 & 5 & 0.75 \\
\hline Vomiting & 1 & 2 & 0.57 \\
\hline Dry mouth & 9 & 7 & 0.54 \\
\hline $\begin{array}{l}\text { Respiratory } \\
\text { depression }\end{array}$ & 0 & 0 & - \\
\hline Hypotension & 28 & 30 & 0.57 \\
\hline Bradycardia & 3 & 4 & 0.71 \\
\hline \multicolumn{4}{|c|}{$\begin{array}{c}\text { Data expressed in numbers. Test done: Pearson Chi-square } \\
\text { test. }(\mathrm{P}=\text { value }<0.05 \text { considered significant). Group A, } \\
\text { patients receiving epidural ropivacaine alone; Group B, } \\
\text { patients receiving ropivacaine with } \\
\text { dexmedetomidine as adjuvant. }\end{array}$} \\
\hline \multicolumn{4}{|c|}{ Table 5. Incidence of Adverse Events } \\
\hline
\end{tabular}

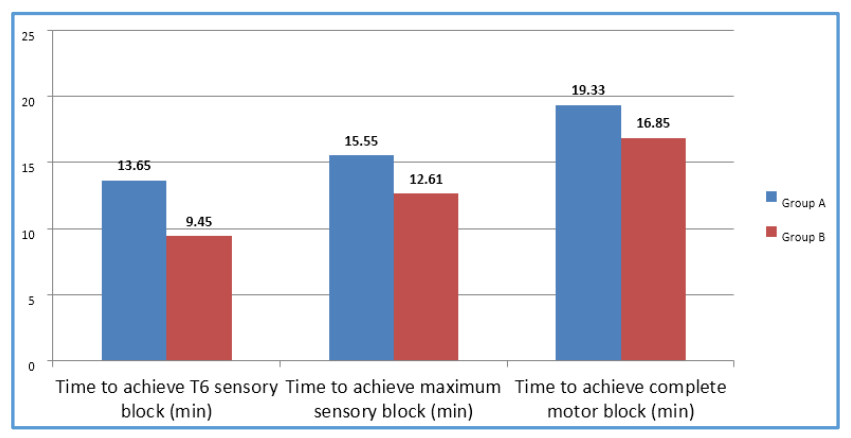

Figure 1. Onset of block. Group A-Patients receiving Epidural Ropivacaine alone; Group B-Patients receiving Ropivacaine with Dexmedetomidine as an Adjuvant

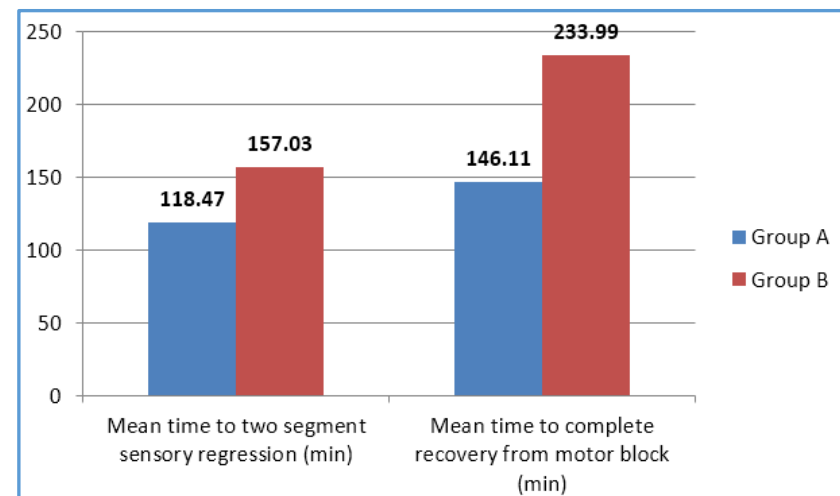

Figure 2. Regression of block. Group A- Patients receiving Epidural Ropivacaine alone; Group B-Patients receiving Ropivacaine with Dexmedetomidine as an Adjuvant

\section{DISCUSSION}

Opioids have been used for years as adjuvants to epidural local anaesthetics owing to its certain advantages such as hastening the onset of block, improved of quality of block and prolongation of postoperative analgesia. Nowadays $\alpha_{2}$ agonist has gained popularity and tends to replace opioids as the former is devoid of respiratory depression, nausea, vomiting or urinary retention. Dexmedetomidine, an $\alpha_{2}$ agonist, offers sedative and analgesic effect while not imparting respiratory depressant effect even at higher doses.11-13

The present study finds earlier achievement of $\mathrm{T}_{6}$-level sensory block (Primary outcome) in patients receiving dexmedetomidine as an adjuvant to epidural ropivacaine compared with those receiving epidural ropivacaine alone $(9.45 \pm 1.04$ versus $13.65 \pm 1.12$ minutes, respectively, $\mathrm{P}<$ $0.05)$. The maximum sensory block reached earlier in dexmedetomidine group compared with ropivacaine alone group $(12.61 \pm 1.45$ versus $15.55 \pm 1.80$ minutes, respectively; $\mathrm{P}<0.05$ ). The time to achieve complete motor block was also found shorter in patients receiving dexmedetomidine as epidural adjuvant. In the present study, sensory block regressed later in group receiving dexmedetomidine compared with group receiving ropivacaine alone (157.03 \pm 7.87 versus $118.47 \pm 7.32$ minutes, respectively, $\mathrm{P}<$ 0.05). Dexmedetomidine has provided superior block characteristics in terms of prolonged time to two segment regression and return of motor power to Bromage scale 1 . Time to first rescue top-up epidural dose was significantly longer in dexmedetomidine group.

Dexmedetomidine as adjuvant to epidural ropivacaine has been reported to hasten the sensory and motor block and delay the block regression, thus prolongs the duration of analgesia compared with ropivacaine alone.14 Dexmedetomidine appears to be superior adjuvant to epidural ropivacaine compared with clonidine ${ }^{7,15}$ or fentanyl. ${ }^{16}$ Dexmedetomidine at a dose of $1 \mathrm{mcg} / \mathrm{kg}$ as adjuvant to levobupivacaine has been found to be either comparable ${ }^{17}$ with or even superior ${ }^{18}$ to fentanyl in achieving prolonged postoperative analgesia and extended arousable sedation while maintaining comparable haemodynamics and acceptable adverse event profile. Chakole $\mathrm{V}$, et al ${ }^{19}$ reported that dexmedetomidine as adjuvant in dose range of 1.0 to 1.5 $\mathrm{mcg} / \mathrm{Kg}$ with epidural bupivacaine substantially prolongs postoperative analgesia with no serious adverse events.

In achieving quicker onset and prolonged duration of block while maintaining haemodynamic stability and better patient comfort, dexmedetomidine was found to be a good alternative to fentanyl ${ }^{20}$ and superior to clonidine ${ }^{21}$ as adjuvants with epidural bupivacaine. The adverse events were reported to be lesser with dexmedetomidine compared with fentanyl. Noteworthy, the incidences of adverse events were far less with $0.5 \mathrm{mcg} / \mathrm{kg}$ than with $1.0 \mathrm{mcg} / \mathrm{kg}$ of dexmedetomidine. ${ }^{20}$ Dexmedetomidine as adjuvant is particularly advantageous in providing arousable sedation besides prolongation of motor and sensory blockade. ${ }^{22}$ Soliman $\mathrm{R}$ and Eltaweel $\mathrm{M}^{23}$ reports about similar advantages but the authors put a caution that epidural dexmedetomidine is associated with a higher incidence of motor block, bradycardia, hypotension, and dry mouth compared with epidural fentanyl.

In the recent years, several studies ${ }^{14,24-26}$ report about promising role of dexmedetomidine as adjuvant to epidural 
ropivacaine. Rastogi $\mathrm{B}$, et $\mathrm{al}^{14}$ found dexmedetomidine to be effective adjuvant with ropivacaine for epidural block in prolonging the duration of motor block and analgesia with adequate sedation and minimal adverse events. They found that addition of dexmedetomidine to epidural ropivacaine resulted in an earlier onset of sensory block $(2.50 \pm 0.877$ vs. $7.00 \pm 1.198$ minutes) and establishment of complete motor blockade ( $17.20 \pm 4.10$ vs. $23.90 \pm 3.57$ minutes) as compared to ropivacaine alone group. Postoperative analgesia was prolonged significantly in the dexmedetomidine adjuvant group (429.25 \pm 58.34 vs. $216.58 \pm 25.56 \mathrm{~min}$.) than ropivacaine alone. Sedation scores were also higher in the dexmedetomidine group. The authors ${ }^{14}$ found that dexmedetomidine in a dose of $0.6 \mathrm{mcg} / \mathrm{kg}$ is a safe and effective adjuvant to ropivacaine in epidural blockade for infraumbilical surgeries. In another study, at doses of 1 $\mu \mathrm{g} / \mathrm{kg}$, dexmedetomidine was found to be better than clonidine as adjuvant to epidural ropivacaine in achieving faster onset of sensory and motor block, prolonged duration of analgesia with better sedation. ${ }^{24}$

In a recent study, Soni $\mathrm{P}^{25}$ reported that the mean onset of sensory block was $15.75 \pm 4.02 \mathrm{~min}$. for ropivacaine alone, $5.7 \pm 2.0 \mathrm{~min}$. for ropivacaine $0.75 \%$ with $1.5 \mathrm{mcg} / \mathrm{kg}$ dexmedetomidine and $9.6 \pm 2.9 \mathrm{~min}$. for ropivacaine plus 2 $\mathrm{mcg} / \mathrm{kg}$ clonidine. The authors concluded that dexmedetomidine appears to be a quite effective adjuvant in epidural anaesthesia in achieving faster onset of sensory blockade with comparable adverse events in comparison to clonidine. ${ }^{25}$ Arora MV, et al ${ }^{26}$ recently reports about faster onset of sensory block with dexmedetomidine compared with neostigmine as adjuvants to epidural ropivacaine. In that study, the time to attain maximum sensory level of $\mathrm{T}_{6}-\mathrm{T}_{7}$ and maximum motor blockade was faster with the use of dexmedetomidine. The achieved maximum level of blockade, intraoperative haemodynamics and sedation was found to be comparable. The authors concluded that dexmedetomidine appears to be superior to neostigmine as an adjuvant to epidural ropivacaine $0.75 \% .{ }^{26}$

Alpha- 2 agonists such as dexmedetomidine block $\mathrm{A} \delta$ and $\mathrm{C}$ fibres as a consequence of an increase in $\mathrm{K}^{+}$conduction in neurons, thereby intensify local anaesthetic conduction block. The variation in block characteristics between the two groups in the present study attributes to synergistic effect 14 as well as the alpha 2 agonistic activity of dexmedetomidine. 27

In the current study, the duration of analgesia was found to be prolonged in patients receiving dexmedetomidine as adjuvant to epidural ropivacaine $(346.12 \pm 17.29$ minutes $)$ compared to those receiving ropivacaine alone (327.98 \pm 17.60 minutes). This difference was found to be significant $(\mathrm{P}<0.05)$. This finding is consistent with the observations of other contemporary studies ${ }^{7,16}$ as well as the recent studies.14,15,24-26 Dexmedetomidine also causes local vasoconstriction owing to post-synaptic $\alpha_{2}$ receptors agonistic activity, thus decreasing local anaesthetic removal from the surroundings of neural structure. This effect is more pronounced in case of dexmedetomidine than clonidine as the former has 800 times more affinity for the post-synaptic $\alpha_{2}$ receptors. Although both of them induce analgesia by activating spinal cholinergic neurons resulting in acetylcholine release.11-13

In the present study, dexmedetomidine was used at a dose of $2 \mathrm{mcg} / \mathrm{kg}$ and the incidences of adverse events are comparable between the two groups. No patient in either of the two groups suffered from respiratory depression. Recent studies $14,15,24-26$ also reflect similar impression regarding adverse event profile.

This study also bears some limitations. We could not measure the plasma concentration of dexmedetomidine. Had it been measured, it might have revealed any possible link with inter-individual variability with the drug's effect. Also, it might help to comment on optimum analgesic plasma concentration of dexmedetomidine. Moreover, we could not establish any synergism or antagonism of the study drugs by isobologram. We have also not studied electromyography or nerve conduction velocity study after offset of motor or sensory block. If studied, it might be possible to detect the actual duration of sensory and motor block. The level of sedation was not assessed directly with BIS monitor in an objective manner. Instead, the occurrence of any of respiratory depression was observed clinically. Further studies are warranted to assess the sedative and analgesic effects of dexmedetomidine in extensive surgeries and especially, in paediatric population having increased sensitivity to sedative drugs. There is also a scope of dose finding study for dexmedetomidine as epidural adjuvant.

\section{CONCLUSION}

To conclude, dexmedetomidine as adjuvant to epidural ropivacaine offers benefit in terms of earlier achievement of $\mathrm{T}_{6}$-level sensory block, quicker onset of motor block, prolonged sensory block and thereby delaying the postoperative first top up of epidural drug compared with epidural ropivacaine alone. Although it prolongs motor block as well, the adverse events are within acceptable limits. Thus, it appears that epidural dexmedetomidine may be utilised as a safe and reliable adjuvant with epidural ropivacaine to provide early onset of sensory block and longer duration analgesia for lower limb surgeries.

\section{REFERENCES}

[1] Oremus K, Safaric Z. The role of epidural anaesthesia and analgesia in surgical practice. Ann Surg 2004;240(3):561-2.

[2] Moraca RJ, Sheldon DG, Thirlby RC. The role of epidural anaesthesia and analgesia in surgical practice. Ann Surg 2003;238(5):663-73.

[3] Mulroy MF, Larkin KL, Hodgson PS, et al. A comparison of spinal, epidural and general anesthesia for outpatient knee arthroscopy. Anesth Analg 2000;91(4):860-4.

[4] McClellan KJ, Faulds D. Ropivacaine: an update on its use in regional anaesthesia. Drug 2000;60(5):1065-93.

[5] Lorenzini C, Moreira LB, Ferreira MB. Efficacy of ropivacaine compared with ropivacaine plus sufentanil for postoperative analgesia after major knee surgery. Anaesthesia 2002;57(5):424-8.

[6] Mann C, Pouzeratte Y, Boccara G, et al. Comparison of intravenous or epidural patient-controlled analgesia in the elderly after major abdominal surgery. Anesthesiology 2000;92(2):433-41. 
[7] Bajwa SJ, Bajwa SK, Kaur J, et al. Dexmedetomidine and clonidine in epidural anaesthesia: a comparative evaluation. Indian J Anaesth 2011;55(2):116-21.

[8] Bhana N, Goa KL, McClellan KJ. Dexmedetomidine. Drugs 2000;59(2):263-8.

[9] Maroof M, Khan SA, Jain D, et al. Evaluation of effect of dexmedetomidine in reducing shivering following epidural anesthesia. Anesthesiology 2004;101:A495.

[10] Korula S, George GM, Ipe S, et al. Epidural anaesthesia and post-operative analgesia for bilateral inguinal mesh hernioplasty: comparison of equipotent doses of ropivacaine and bupivacaine. Saudi J Anaesth 2011;5(3):277-81.

[11] Villela NR, Nascimento P. Dexmedetomidine in anaesthesiology. Rev Bras Anestesiol 2003;53(1):97113.

[12] Kaur M, Singh PM. Current role of dexmedetomidine in clinical anesthesia and intensive care. Anesth Essays Res 2011;5(2):128-33.

[13] Sudheesh K, Harsoor SS. Dexmedetomidine in anaesthesia practice: a wonder drug? Indian J Anaesth 2011;55(4):323-4.

[14] Rastogi B, Singh VP, Mangla D, et al. Dexmedetomidine as an adjuvant to epidural $0.75 \%$ ropivacaine in patients undergoing infraumbilical surgery: a clinical study. Glob Anesth Perioper Med 2015;1(1):19-23.

[15] Thimmappa M, Madhusudhana R, Potli S, et al. A comparative study of epidural ropivacaine $0.75 \%$ alone with ropivacaine plus clonidine and ropivacaine plus dexmedetomidine for lower abdominal and lower limb surgeries. World Journal of Pharmacy and Pharmaceutical Sciences 2014;3(4):1218-30.

[16] Bajwa SJS, Arora V, Kaur J, et al. Comparative evaluation of dexmedetomidine and fentanyl for epidural analgesia in lower limb orthopedic surgeries. Saudi J Anaesth 2011;5(4):365-70.

[17] Aziz MMA, Abdelfatah AM, Hamid HMA. Ultrasoundguided caudal analgesia using fentanyl versus dexmedetomidine as an adjuvant for levobupivacaine in infraumbilical pediatric surgeries. Ain-Shams J Anaesthesiol 2016;9(4):542-8.

[18] Elfawal SM, Abdelaal WA, Hosny MR. A comparative study of dexmedetomidine and fentanyl as adjuvants to levobupivacaine for caudal analgesia in children undergoing lower limb orthopedic surgery. Saudi J Anaesth 2016;10(4):423-7.
[19] Chakole V, Kumar P, Sharma M. Effect of dexmedetomidine on postoperative analgesia and haemodynamics when added to bupivacaine $0.5 \%$ in epidural block for pelvic and lower limb orthopedic surgeries. International Journal of Contemporary Medical Research 2016;3(8):2239-43.

[20] Hosalli V, Ganeshnavar AK, Sindhura N, et al. Comparison of two different doses of dexmedetomidine with bupivacaine in paediatric caudal anesthesia for infraumbilical surgeries: a randomized double blind clinical study. Intl J Clin Diag Res 2016;4(3):III.

[21] Shaikh SI, Mahesh SB. The efficacy and safety of epidural dexmedetomidine and clonidine with bupivacaine in patients undergoing lower limb orthopedic surgeries. J Anaesthesiol Clin Pharmacol 2016;32(2):203-9.

[22] Shahi V, Verma AK, Agarwal A, et al. A comparative study of magnesium sulfate vs dexmedetomidine as an adjunct to epidural bupivacaine. J Anaesthesiol Clin Pharmacol 2014;30(4):538-42.

[23] Soliman R, Eltaweel M. Comparative study of dexmedetomidine and fentanyl as an adjuvant to epidural bupivacaine for postoperative pain relief in adult patients undergoing total knee replacement: a randomized study. J Anesthesiol Clin Sci 2016;5:1.

[24] Arunkumar S, Hemanth Kumar VR, Krishnaveni N, et al. Comparison of dexmedetomidine and clonidine as an adjuvant to ropivacaine for epidural anesthesia in lower abdominal and lower limb surgeries. Saudi J Anaesth 2015;9(4):404-8.

[25] Soni P. Comparative study for better adjuvant with ropivacaine in epidural anesthesia. Anesth Essays Res 2016;10(2):218-22.

[26] Arora MV, Khan MZ, Bhadwal A, et al. Comparison of epidural dexmedetomidine and neostigmine used as adjuvant to ropivacaine in lower limb surgeries. J Evolution Med Dent Sci 2016;5(84):6264-9.

[27] Grewal A. Dexmedetomidine: new avenues. J Anaesthesiol Clin Pharmacol 2011;27(3):297-302. 